\title{
$\beta$-catenin is up-expressed and predicts poor overall survival of breast cancer
}

\author{
Lizhou Jia $^{1,2}$, Xiaobing Yang ${ }^{3}$, Wei Zhao ${ }^{3 *}$ \\ ${ }^{1}$ Key Laboratory of Antibody Technique of National Health and Family Planning Commission, Nanjing, Jiangsu 211166, China; \\ ${ }^{2}$ Department of Pathology, Nanjing Medical University, Nanjing, Jiangsu 211166, China; \\ ${ }^{3}$ Department of Pathology, Nanjing First Hospital, Nanjing Medical University, Nanjing, Jiangsu 210000, China
}

\begin{abstract}
Breast cancer (BC) is one of the most common malignant tumors in women. The majority of BC cells contain at least one or more up-expressed oncogene. $\beta$-catenin is found overexpressed in various epithelial cell cancers and has the function of inducing cancer cell proliferation, invasion and metastasis. However, the expression of $\beta$-catenin and its prognostic value in BC is not yet clear. In this study, mRNA and $\beta$-catenin proteins expressed in BC tissues have been explored. Quantitative real-time polymerase chain reaction (qRT-PCR) and immunohistochemistry (IHC) on tissue microarrays (TMA) were performed to examine the level of $\beta$-catenin mRNA and protein in BC tissues. The association between $\beta$-catenin and clinical characteristics and prognostic value were also explored. $\beta$-catenin mRNA and protein were found over-expressed in BC tissues when compared with matched tumor neighbor tissues. A high degree of $\beta$-catenin staining in $\mathrm{BC}$ tissues was significantly associated with tumor size, Ki67 expression, lymph node status and TNM stage. $\beta$-catenin up-expression was also able to predict poor overall survival (OS) rates. These results indicated that $\beta$-catenin may be a useful prognostic molecular biomarker for BC patients.
\end{abstract}

Keywords: $\beta$-catenin, breast cancer, prognosis, biomarker

\section{INTRODUCTION}

Breast cancer (BC) is one of the most common malignant tumors in women, and the incidence is increasing, with more than 1.2 million new cases diagnosed each year worldwide ${ }^{[1-2]}$. $\beta$-catenin is the ultimate signaling molecule in theWnt/ $\beta$-catenin signaling pathway ${ }^{[3-5]}$. In the absence of Wnt ligands, most $\beta$-catenin protein in the cytoplasm are able to combine with E-cadherin in the cell membrane, as well as with APC, Axin and GSK3 and CK I , causing the degradation of composites, and possibly the phosphorylation of different residues and the deg-

*Correspondence to: Wei Zhao, PhD. Department of Pathology, Nanjing First Hospital, Nanjing Medical University, Nanjing 210000, Jiangsu, China. TEL:0086-25-52887054 E-mail:zhaowei_njmu@163.com Conflict of interests: The authors have declared no conflict of interests. radation of $\beta$-catenin. The $\beta$-catenin signal has been confirmed as playing an important role in the development and transformation of tumors, such as colon cancer, pancreatic cancer, breast cancerand gastric cancer ${ }^{[3,6-7]}$. It has been reported that the Wnt/ $\beta$-catenin signaling pathway is involved in the proliferation, invasion, metastasis and resistance of gastric cancer cells ${ }^{[8]}$. Meanwhile, interference with the $\mathrm{Wnt} / \beta$-catenin signaling pathway can inhibit the proliferation, invasion and metastasis of gastric cancer and increase the sensitivity of cancer cells to chemotherapy drugs ${ }^{[9]}$.

At present, little is known about the level of $\beta$-catenin expression, and its prognostic value in $\mathrm{BC}$ is not yet clear. Therefore, the relationship between $\beta$-catenin expression, clinical characteristics, and overall survival rates for $\mathrm{BC}$ have been explored in this study. 


\section{MATERIALS AND METHODS}

\section{Patient specimens}

Two hundred and fifty-five cases of BC were obtained from the department of pathology, Nanjing First Hospital, from 2008 to 2012. These samples include 255 cases of cancer tissue with 43 cases of matched tumor neighbor tissues. Clinical information for tissue donor patients included age, location, tumor size, TNM stage, ER/PR/HER2, $\mathrm{Ki}-67$, histologic grade, lymph node status, metastasis and overall survival. The study protocol was approved by the hospital's Human Research Ethics Committee.

\section{Quantitative real-time polymerase chain re- action (qRT-PCR)}

$\beta$-catenin expression levels in 32 pairs of human $\mathrm{BC}$ tissues were compared with matched tumor tissues. Cell RNA was extracted by TRIzol reagent (Invitrogen, USA) and then reverse transcribed into cDNA using a PrimeScript ${ }^{\mathrm{TM}} \mathrm{RT}$ reagent kit (Takara, Japan), according to the manufacturer's protocol. Human GAPDH served as the internal control. The primers used in the study were as follows; GAPDH F: 5' -GAAGGTGAAGGTCGGAGTC-3', and R: $5^{\prime}$-GAAGATGGTGATGGGATTTC- $3^{\prime}$. $\beta$-catenin F, 5'- GAAACGGCTTTCAGTTGAGC -3', and R, 5'-CTGGCCATATCCACCAGAGT -3' (Genescript. China). qRT-PCR was performed on an ABIPRISM 7500HT Sequence Detection System (Applied Biosystems, USA) in 96-well plates. Relative expression levels were calculated as ratios normalized against those of GAPDH. Results were normalized to respective internal controls. The Ct-value for each sample was calculated using the $\Delta \Delta \mathrm{Ct}$ method, and results were expressed as $2-^{-\Delta \Delta \mathrm{Ct}}$.

\section{Tissue microarrays construction (TMA) and immunohistochemistry}

The tissues from $255 \mathrm{BC}$ and 43 matched tumoradjacent tissues were formalin-fixed and paraffinembedded for the study. TMA was produced in the department of pathology, Nanjing first hospital, Nanjing, Jiangsu, China, using the Tissue system Quick-Ray (Unitma, Korea) manual. Core tissue biopsies (2 $\mathrm{mm}$ in diameter) were taken from individual paraffin-embedded $\mathrm{BC}$ and produced in the recipient paraffin blocks. The methods and IHC score can be seen in our previous articles. $\beta$-catenin was detected using amonoclonal antibody mouse antihuman $\beta$-catenin (dilution 1:100) (Santa Cruz, USA).

\section{Statistical analysis}

The statistical analysis was performed using SPSS 18.0 statistical software (SPSS Inc., Chicago, IL). The Student's $t$-test and Pearson $\chi^{2}$ test were used to determine the statistical significance between the different groups. Both the Kaplan-Meier method and a LogRrank test were used to evaluate the significant difference between overall survival(OS) in patients. The univariate and multivariate hazard ratios for the variables were analyzed by a cox proportional hazards model. A two-tailed $P$-value of less than 0.05 was considered as statistically significant.

\section{RESULTS}

\section{The level of $\beta$-catenin mRNA expression of} BC tissues

The expression level of $\beta$-catenin mRNA through qRT-PCR in 32 pairs of breast cancer tissues were detected. The results showed that $\beta$-catenin mRNA was over-expressed in $\mathrm{BC}$ tissues compared to matched tumor neighbor tissues, with an average upregulation of $2.176 \pm 1.773(P<0.001$, Fig.1 $)$.

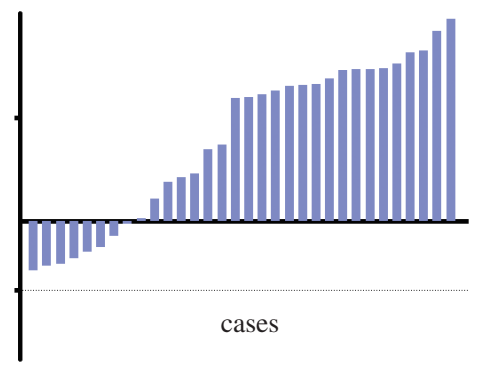

Fig. $1 \beta$-catenin mRNA expression in 32 pairs breast cancer tissues. $\beta$-catenin mRNA expression was detected by qRT-PCR and normalized to GAPDH.

\section{$\beta$-catenin protein expression of $\mathrm{BC}$ tissues compared with tumor-adjacent tissues by IHC}

$\beta$-catenin protein was localized to the cell membrane and cytoplasm (Fig. 2). Using the x-tile software for TMAs data analysis(http://www.tissuearray.org/ rimmlab) ${ }^{[10]}$, the cutoff point was defined according to $\mathrm{OS}$ in BC patients. A cutoff value of 110 was selected, 0-110 were considered low expression, and 111-300 were considered high expression.

Highly expressed $\beta$-catenin expression in $\mathrm{BC}$ tissues $(159 / 255,62.35 \%)$ were higher than tumor-adjacent tissues (8/43, 18.61\%), $\chi^{2}=33.98, P<0.001$ (Table 1).

\section{Association of $\beta$-catenin protein expression with clinicopathologic characteristics in BC patients}

As shown in Table 2, high $\beta$-catenin staining in BC 


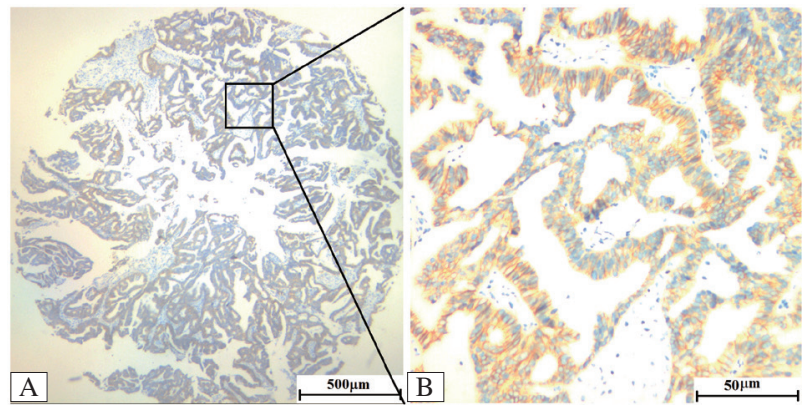

Fig. 2 Representative pattern of $\beta$-catenin protein expression in BC tissues on TMA sections. High expression of $\beta$-catenin in breast cancer tissues (IHC score, 270), $\beta$-catenin staining with $\times 4$ $($ bar $=500 \mu \mathrm{m})(\mathrm{A})$, with $\times 20($ bar $=50 \mu \mathrm{m})(\mathrm{B})$.

tissues was significantly associated with tumor size $\left(\chi^{2}=5.066, P=0.012\right)$, Ki-67 expression $\left(\chi^{2}=4.384\right.$, $P=0.029)$, lymph node status $\left(\chi^{2}=4.304, P=0.032\right.$ and TNM stage $\left(\chi^{2}=4.904, P=0.026\right)$. However, the
Table $1 \beta$-catenin expression in $\mathrm{BC}$ tissues compared with tumor-adjacent tissues

\begin{tabular}{lrrr}
\hline \multirow{2}{*}{ Group } & \multirow{2}{*}{$n$} & \multicolumn{2}{c}{$\beta$-catenin expression $[n(\%)]$} \\
\cline { 3 - 4 } & & Low or no & \multicolumn{1}{c}{ High } \\
\hline Breast tissues cancer & 255 & $96(37.65)$ & $159(62.35)$ \\
Tumor-adjacent tissues & 43 & $35(81.39)$ & $8(18.61)$ \\
\hline
\end{tabular}

$\chi^{2}=33.98, \mathrm{P}<0.001$.

present study did not find a significant association between $\beta$-catenin protein expression and tumor location, age, pathology stage, ER, PR, HER2, metastasis, etc (Table 2).

\section{Up-expression of $\beta$-catenin protein correlates with poor OS of $B C$ patients}

To evaluate the relationship between $\beta$-catenin and prognostic factors in $\mathrm{BC}$ patients, both univariate and

Table 2 Associations between high $\beta$-catenin expression and clinicopathologic characteristics in BC patients

\begin{tabular}{|c|c|c|c|c|c|}
\hline \multirow{2}{*}{ Characteristic } & \multirow{2}{*}{$n$} & \multicolumn{2}{|c|}{$\beta$-catenin expression $[n(\%)]$} & \multirow{2}{*}{$\chi^{2}$} & \multirow{2}{*}{$P$ valae } \\
\hline & & Low or no & High & & \\
\hline Tumor location & & & & 0.550 & 0.734 \\
\hline Left & 154 & $70(49.35)$ & $84(54.55)$ & & \\
\hline Right & 101 & $43(42.57)$ & $58(57.43)$ & & \\
\hline Age & & & & 2.198 & 0.087 \\
\hline Premenopausal & 110 & $55(50.00)$ & $55(50.00)$ & & \\
\hline Postmenopausal & 145 & $62(42.76)$ & $83(57.24)$ & & \\
\hline Pathology stage & & & & 0.137 & 0.341 \\
\hline 1 & 47 & $20(42.55)$ & $27(57.45)$ & & \\
\hline 2 & 159 & $70(45.28)$ & $89(55.97)$ & & \\
\hline 3 & 49 & $20(40.81)$ & $29(59.18)$ & & \\
\hline Tumor size & & & & 5.066 & 0.012 \\
\hline$\leqslant 2 \mathrm{~cm}$ & 59 & $37(62.72)$ & $22(37.29)$ & & \\
\hline$>2 \mathrm{~cm}$ & 195 & $82(42.05)$ & $114(58.46)$ & & \\
\hline ER & & & & 1.473 & 0.178 \\
\hline Positive & 98 & 38 (38.78) & $60(61.22)$ & & \\
\hline Negative & 157 & $74(47.13)$ & $83(52.87)$ & & \\
\hline $\mathrm{PR}$ & & & & 0.944 & 0.379 \\
\hline Positive & 125 & $51(43.20)$ & $74(59.20)$ & & \\
\hline Negative & 130 & $62(48.50)$ & $68(51.50)$ & & \\
\hline HER2 & & & & 0.042 & 0.817 \\
\hline Positive & 93 & $43(46.20)$ & $50(53.80)$ & & \\
\hline Negative & 162 & $73(45.06)$ & $89(54.94)$ & & \\
\hline $\mathrm{Ki}-67$ & & & & 4.384 & 0.029 \\
\hline Positive & 136 & $56(41.18)$ & $80(58.82)$ & & \\
\hline Negative & 119 & $61(51.26)$ & $58(48.74)$ & & \\
\hline Lymph node status & & & & 4.304 & 0.032 \\
\hline NO & 111 & 66 (59.46) & $45(40.54)$ & & \\
\hline $\mathrm{N} 1+2+3$ & 144 & $61(42.36)$ & $83(57.64)$ & & \\
\hline \multicolumn{6}{|l|}{ Metastasis } \\
\hline M0 & 64 & 27 (42.19) & $37(57.81)$ & 0.023 & 0.487 \\
\hline M1 & 191 & $83(43.46)$ & $108(56.54)$ & & \\
\hline TNM stage & & & & 4.904 & 0.026 \\
\hline 1 & 90 & $46(51.11)$ & $44(48.89)$ & & \\
\hline 2 & 97 & $43(44.33)$ & $54(55.67)$ & & \\
\hline 3 & 68 & $20(29.41)$ & $48(70.59)$ & & \\
\hline
\end{tabular}


multivariate analyses have been used(Table 3). High $\beta$-catenin protein expression (HR: $3.416,95 \% \mathrm{CI}$ : $1.432-3.243 ; P<0.001)$ was associated with a shorter survival in univariate analysis, along with tumor size (HR: $2.962,95 \%$ CI: $1.189-3.604 ; P=0.028)$, Ki67 expression (HR: 3.483 , 95\% CI: 1.388-3.432; $P=0.021$ ), lymph node status (HR: $2.988,95 \% \mathrm{CI}$ : 1.521-2.097; $P=0.042$ ), metastasis (HR: $2.342,95 \%$ CI: $1.126-2.963 ; P=0.034)$ and TNM stage (HR: 4.012 , 95\% CI: $1.623-3.624 ; P<0.001)$. In multivariate analysis, up-expressed $\beta$-catenin (HR: $2.634,95 \%$ CI: $1.012-3.023 ; P=0.011$ ), Ki-67 expression (HR: 2.415, 95\% CI: $1.023-2.362 ; P=0.022)$ and TNM stage (HR: $2.823,95 \%$ CI: $1.402-3.243 ; P=0.021$ ) was associated with poor OS. Furthermore, data from the Kaplan-Meier survival curves showed that high $\beta$-catenin expression was significantly associated with poor OS in BC patients (Fig.3). These results indicated that $\beta$-catenin is a prognostic marker for $\mathrm{BC}$ patients.

\section{DISCUSSION}

$\mathrm{BC}$ is the most common malignancy in women worldwide ${ }^{[11-12]}$. According to statistics, the incidence of $\mathrm{BC}$ in China is 169000 , which ranks it as the second most common in malignant tumor ${ }^{[13]}$. The occurrence of $\mathrm{BC}$ is closely related to environment and lifestyle, including nutritional status andweight loss, which has been confirmed as an effective primary prevention measure. Furthermore, a reduction in mortality and improvements in the survival of $\mathrm{BC}$ patients could be improved through the effective screening of higher risk groups ${ }^{[14]}$.

$\beta$-cateninmainly exists in the cell membrane and cytoplasm of various types of cells and has many functions ${ }^{[15]}$. The main function of $\beta$-catenin is to regulate adhesion between cells causing the expression of certain genes. The expression level of $\beta$-catenin

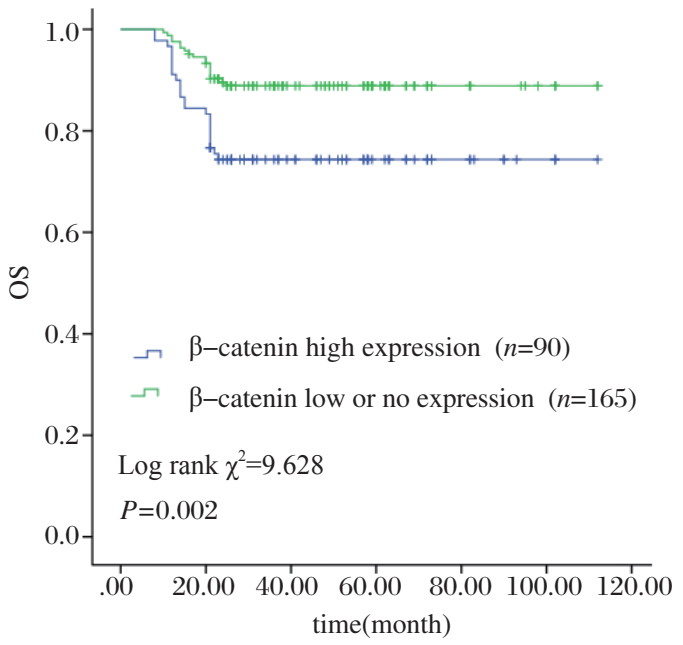

Fig. 3 Survival curves for breast cancer using the KaplanMeier method and log-rank test. Overall survival curves for patients with $\beta$-catenin high expression (blue line, 1), and low or no expression (green line, 2).

Table 3 Associations between high $\beta$-catenin expression and clinicopathologic characteristics in BC patients

\begin{tabular}{|c|c|c|c|c|c|c|}
\hline \multirow{2}{*}{ prognostic indicator } & \multicolumn{3}{|c|}{ Univariate analysis } & \multicolumn{3}{|c|}{ Multivariate analysis } \\
\hline & HR & $\mathrm{P}>|\mathrm{z}|$ & $95 \% \mathrm{CI}$ & HR & $P>|z|$ & $95 \% \mathrm{CI}$ \\
\hline \multicolumn{7}{|l|}{$\beta$-cateninex pression } \\
\hline High vs. Low or no & 3.416 & $<0.001$ & $1.432-3.243$ & 2.634 & 0.011 & $1.012-3.023$ \\
\hline \multicolumn{7}{|l|}{ Location } \\
\hline left vs.right & 0.93 & 0.572 & $0.534-1.285$ & & & \\
\hline \multicolumn{7}{|l|}{ Age } \\
\hline premenopausal vs.postmenopausal & 0.834 & 0.926 & $0.501-1.934$ & & & \\
\hline \multicolumn{7}{|l|}{ Pathology stage } \\
\hline 1 vs. 2 vs.3 & 0.623 & 0.623 & $0.531-1.383$ & & & \\
\hline \multicolumn{7}{|l|}{ Tumor size } \\
\hline$\leq 2 \mathrm{CM}$ vs. $>2 \mathrm{CM}$ & 2.962 & 0.028 & $1.189-3.604$ & & & \\
\hline \multicolumn{7}{|l|}{ ER } \\
\hline Positive $v s$. negative & 1.834 & 1.013 & $0.623-2.433$ & & & \\
\hline Positive $v s$. negative & 0.823 & 0.523 & $0.412-1.653$ & & & \\
\hline \multicolumn{7}{|l|}{ HER2 } \\
\hline Positive $v s$. negative & 1.153 & 1.823 & $0.595-2.623$ & & & \\
\hline \multicolumn{7}{|l|}{$\mathrm{Ki}-67$} \\
\hline Positive $v s$. negative & 3.483 & 0.021 & $1.388-3.432$ & 2.415 & 0.022 & $1.023-2.362$ \\
\hline \multicolumn{7}{|l|}{ Lymph node status } \\
\hline $\mathrm{N} 0$ vs. $\mathrm{N} 1+2+3$ & 2.988 & 0.042 & $1.521-2.097$ & & & \\
\hline \multicolumn{7}{|l|}{ Metastasis } \\
\hline M0 vs. M1 & 2.342 & 0.034 & $1.126-2.963$ & & & \\
\hline \multicolumn{7}{|l|}{ TNM stage } \\
\hline 1 vs. 2 vs. 3 & 4.012 & $<0.001$ & $1.623-3.624$ & 2.823 & 0.021 & $1.402-2.234$ \\
\hline
\end{tabular}


can also directly regulate the Wnt signaling pathway. When $\beta$-catenin degradation is blocked, this can lead to an accumulationand enters the nucleus. Thereby leads to the occurrence of cancer by activating the Wnt signaling pathway ${ }^{[9,16]}$.

This study, explored $\beta$-catenin mRNA and protein levels in BC tissues through qRT-PCR and IHC. $\beta$-catenin mRNA levels were much high than in matched neighboring matched tissues. The results were similar toNadanaka's research ${ }^{[17]}$, which studied the increased cytoplasmic and nuclear $\beta$-catenin levels observed in basal-like breast cancers in vitro. The study further examined the protein levels in $\mathrm{BC}$ patients through microarray examination, which included 255 samples of BC tissue, and associated clinical and follow-up data. As with mRNA expression, high $\beta$-catenin protein expression was detected in a larger proportion of BC tissues $(159 / 255,62.35 \%)$ than in matched tumor tissues $(8 / 43,18.61 \%)$. Furthermore, the authors also found that high $\beta$-catenin staining in BC tissues was significantly associated with tumor size, Ki-67 expression, lymph node status, TNM stage. $\beta$-catenin up-expression was also a predictor of poor OS.

The mutation and abnormal expression of $\beta$-catenin is known to be found in many tumors, so $\beta$-catenin is highly likely tobe related to the occurrence and development of these tumors. Ma et al ${ }^{[18]}$. reported that $\beta$-catenin may play a critical role in BC immunity, particularly in HER2-enriched and triple negative BC (TNBC), and may serve as a potential target for regulating immune infiltrates in breast cancer. Others reported that the abnormal expression of $\beta$-catenin was associated with poorer prognoses in cancer patients ${ }^{[19-20]}$. In the present study, the relationship between $\beta$-catenin and HER2 expression could not be found. This may be due to the differences in the molecular characteristics and epidemiology of BC. These reports nonetheless supported our hypothesis, that $\beta$-catenin may be a useful prognostic molecular biomarker for BC patients.

This study had several limitations: it is the lacking of an appropriate assay to explore the role of $\beta$-catenin in vivo and in vitro, and a further examination is needed to explore the molecular mechanism of $\beta$-catenin in BC.

\section{References}

[1] Lambert AW, Wong CK, Ozturk S, et al. Tumor cellderived periostin regulates cytokines that maintain breast cancer stem cells[J]. Mol Cancer Res, 2016, 14(1):103113

[2] Lin H, Huang JF, Qiu JR, et al. Significantly upregulated TACSTD2 and Cyclin D1 correlate with poor prognosis of invasive ductal breast cancer[J]. Exp Mol Pathol,
2013, 94: 73-78.

[3] Chang YH, Chu TY, Ding DC. WNT/beta-Catenin signaling pathway regulates non-tumorigenesis of human embryonic stem cells co-cultured with human umbilical cord mesenchymal stem cells[J]. Sci Rep, 201, 7: 41913.

[4] Pearlman RL, Montes DOM, Pal HC ,et al. Potential therapeutic targets of epithelial-mesenchymal transition in melanoma[J]. Cancer Lett, 2017, 391:125-140.

[5] Stoyanova T, Goldstein AS, Cai H, et al. Regulated proteolysis of Trop2 drives epithelial hyperplasia and stem cell self-renewal via $\beta$-catenin signaling[J]. Genes Dev, 2012, 26(20):2271-2285.

[6] Zhang M, Wang D, Zhu T, et al. RASSF4 overexpression inhibits the proliferation, invasion, EMT, and Wnt signaling pathway in osteosarcoma cells[J]. Oncol Res,2017,25(1):83-91.

[7] Choi YJ, Kim N and Chang H, et al. Helicobacter pylori-induced epithelial-mesenchymal transition, a potential role of gastric cancer initiation and an emergence of stem cells[J]. Carcinogenesis, 2015, 36: 553-563.

[8] Cong N, Du P, Zhang A, et al. Downregulated microRNA-200a promotes EMT and tumor growth through the wnt/beta-catenin pathway by targeting the E-cadherin repressors ZEB1/ZEB2 in gastric adenocarcinoma[J]. Oncol Rep, 2013, 29: 1579-1587.

[9] Zhao L, Li W,Zang W, et al. JMJD2B promotes epithelial-mesenchymal transition by cooperating with betacatenin and enhances gastric cancer metastasis[J]. Clin Cancer Res, 2013,19: 6419-6429.

[10] Zhao W, Zhu H,Zhang S, et al. Trop2 is overexpressed in gastric cancer and predicts poor prognosis. Oncotarget, 2016, 7: 6136-6145.

[11] Holt K. It does matter: breast cancer is the second leading cause of cancer deaths in American women (American Cancer Society, 2008). Assuming an average life span of 85 years, one in eight U.S. women will be diagnosed with breast cancer[J]. Nurs Womens Health, 2010, 14: 34-41.

[12] Zeichner SB, Terawaki H ,Gogineni K. A review of systemic treatment in metastatic triple-negative breast cancer[J]. Breast Cancer (Auckl) , 2016, 10: 25-36.

[13] Nomura S, Hwang YT, Gomez SL, et al. Dietary intake of soy and cruciferous vegetables and treatment-related symptoms in Chinese-American and non-Hispanic White breast cancer survivors[J]. Breast Cancer Res Treat, $2018,168(2): 467-479$.

[14] McGuire S. World Cancer Report 2014. Geneva, Switzerland: World Health Organization, International Agency for Research on Cancer, WHO Press, 2015[J]. Adv Nutr, 2016, 7: 418-419.

[15] Mishra J, Das JK, Kumar N. Janus kinase-3 regulates adherens junction and epithelial mesenchymal transition through Beta-catenin[J]. J Biol Chem, 2017,292(40):16406-16419

[16] Kavak E, Najafov A,Ozturk N, et al. Analysis of the Wnt/B-catenin/TCF4 pathway using SAGE, genomewide microarray and promoter analysis: Identification of 
BRI3 and HSF2 as novel targets[J]. Cell Signal, 2010, 22: $1523-1535$

[17] Nadanaka S, Kinouchi H, Kitagawa H. Chondroitin sulfate-mediated $\mathrm{N}$-cadherin/ $\beta$-catenin signaling is associated with basal-like breast cancer cell invasion[J]. $J$ Biol Chem,2018,293(2):444-465

[18] Ma X, Zhao X, Yan W, et al. Tumor-infiltrating lymphocytes are associated with beta-catenin overexpression in breast cancer[J]. Cancer Biomark, 2018, 21: $639-650$

[19] Huang R, Han J ,Liang X, et al. Androgen receptor ex- pression and bicalutamide antagonize androgen receptor inhibit beta-catenin transcription complex in estrogen receptor-negative breast cancer[J]. Cell Physiol Biochem, 2017, 43: 2212-2225.

[20] Zhou T, Zhang A,Kuang G, et al. Baicalin inhibits the metastasis of highly aggressive breast cancer cells by reversing epithelial-to-mesenchymal transition by targeting beta-catenin signaling[J]. Oncol Rep , 2017, 38: 3599-3607.

(Received 07 Feburary 2018, Revised 04 April 2018, Accepted 17 April 2018) 